\title{
SMOKING, HEALTH CAPITAL, AND LONGEVITY: EVALUATION OF PERSONALIZED CESSATION TREATMENTS IN A LIFECYCLE MODEL WITH HETEROGENEOUS AGENTS
}

\author{
Li-Shiun Chen \\ Ping Wang \\ Yao Yao
}

Working Paper 23820

http://www.nber.org/papers/w23820

\author{
NATIONAL BUREAU OF ECONOMIC RESEARCH \\ 1050 Massachusetts Avenue \\ Cambridge, MA 02138 \\ September 2017
}

We would like to thank Jerome Adda, Isaac Ehrlich, Chad Jones, Don Kenkel, and Rody Manuelli for helpful comments and suggestions. Financial support from R01DA038076, KL2RR024994 and K08DA030398 (Chen) and from the Weidenbaum Center on the Economy, Government, and Public Policy (Wang) is gratefully acknowledged. Rongsheng Tang has provided excellent research assistance. The views expressed herein are those of the authors and do not necessarily reflect the views of the National Bureau of Economic Research.

NBER working papers are circulated for discussion and comment purposes. They have not been peer-reviewed or been subject to the review by the NBER Board of Directors that accompanies official NBER publications.

(C) 2017 by Li-Shiun Chen, Ping Wang, and Yao Yao. All rights reserved. Short sections of text, not to exceed two paragraphs, may be quoted without explicit permission provided that full credit, including $\odot$ notice, is given to the source. 
Smoking, Health Capital, and Longevity: Evaluation of Personalized Cessation Treatments in a Lifecycle Model with Heterogeneous Agents

Li-Shiun Chen, Ping Wang, and Yao Yao

NBER Working Paper No. 23820

September 2017

JEL No. D91,E20,I10

\title{
$\underline{\text { ABSTRACT }}$
}

Cigarette smoking leads to large healthcare and morbidity costs, and mortality losses, and smoking cessation plays a key role in reducing health risk and economic costs. While medical evidence suggests that some smokers are more likely to respond to medication treatment than others depending on genetic markers, it remains unexplored whether pharmacogenetic testing is cost-effective in treating potential quitters of smoking. We address this knowledge gap by developing a lifecycle model in which individuals make smoking, health investment and consumption-savings decisions. Depending on an individual's genotype, smoking may bring enjoyment but deteriorates one's health, and the dynamic evolution of health capital determines life expectancy. In addition to heterogeneous genotypes, individuals also differ in demographics. We calibrate this model to fit key economic and medical observations in the U.S. We then propose three smoking cessation policies, two with standard treatments and one personalized depending on genetic markers, all under the same program costs. We construct two unified measures of effectiveness and subsequently compute the cost-effectiveness ratio. We find that personalized treatment is the most cost-effective: for each dollar of program cost, it generates $\$ 8.94$ value in effectiveness, which is $22-45 \%$ higher than those under standard treatments.

\author{
Li-Shiun Chen \\ School of Medicine \\ Washington University in St. Louis \\ St. Louis, MO 63130 \\ chenli@psychiatry.wustl.edu \\ Ping Wang \\ Department of Economics \\ Washington University in St. Louis \\ Campus Box 1208 \\ One Brookings Drive \\ St. Louis, MO 63130-4899 \\ and NBER \\ pingwang@wustl.edu
}

Yao Yao

School of Economics and Finance

Victoria University of Wellington

Wellington, New Zealand

Yao.Yao@vuw.ac.nz 


\section{Introduction}

Cigarette smoking is a leading preventable threat for global public health (Knopik et al., 2012; McClure et al., 2013; Jha, et al., 2013; Whiteford et al., 2013). The costs of smoking include healthcare costs, morbidity (productivity) costs, and mortality losses (Max et al., 2004; Barendregt et al., 1997; Miller et al., 1999). ${ }^{1}$ While healthcare costs for smokers at a given age are about 40 percent higher than those for nonsmokers in the short term (Barendregt et al., 1997), smoking-attributable healthcare costs are estimated to be 6-8 percent of American personal health expenditure (Miller et al., 1999). The estimated total costs of smoking in California in 1999 is $\$ 475$ per resident or $\$ 3,331$ per smoker, with 54 percent due to healthcare, 10 percent due to lost productivity from illness and 36 percent due to premature deaths, where the value of life lost per death averaged $\$ 132,000$ or 12.4 years (Max et al., 2004). In addition, there is a significant wage gap between smokers and nonsmokers, a negative wage effect of tobacco about 10 percent for males using data from the Netherlands (van Ours, 2004). Furthermore, it is evident that the costs of smoking are higher when including the sizable negative external effects associated with second hand smoking. ${ }^{2}$

Thus, smoking cessation plays a key role in diminishing the increased health risk and economic costs (Jha, et al., 2013). Recent research shows that use of genetic markers in smoking cessation treatments has great promise (Chen and Bierut, 2013; Kortmann et al., 2010; Bough et al., 2014; Epstein, 2008). Different pharmacokinetic and pharmacodynamic markers have been implicated in personalized therapeutic approaches including nicotinic acetylcholine receptor genes (nAChRs) based on the Genome Wide Association Study (GWAS) discovery (Tanner et al., 2015; Gold and Lerman, 2012). For example, variants in the genes encoding the $\alpha 5-\alpha 3-\beta 4$ nicotinic receptor subunits show promise as a biomarker for predicting increased risk for developing nicotine dependence (Liu et al., 2010; Saccone et al., 2010; Tobacco and Genetics Consortium, 2010; Thorgeirsson et al., 2010), and delayed smoking cessation (Chen et al., 2015). ${ }^{3}$ When receiving treatments, some smokers are more likely to respond to medication treatment than others (Chen et al., 2012; Bergen

\footnotetext{
${ }^{1}$ Economics of Tobacco Toolkit (WHO, 2011) provides a comprehensive review of methods of estimating the economic costs of smoking.

${ }^{2}$ Pickett et al. (2006) documents that 45.9 percent of American in counties without smoke-free law are exposed to secondhand smoke using data from the 1999-2002 National Health and Nutrition Examination Survey. They find that even in counties with extensive smoke-free law coverage, such exposure is still nonnegligible (12.5\%).

${ }^{3}$ They also help predicting increased risks for lung cancer (Amos et al., 2008; Thoreirsson et al., 2008) and chronic obstructive pulmonary disease (COPD) (Pillai et al., 2009).
} 
et al., 2013). ${ }^{4}$

Leveraging advances in genomics, the goal of precision medicine is to personalize treatments based on an individual's unique characteristics to maximize benefits and minimize risks resulting from side effects. Whether pharmacogenetic testing should be implemented in the clinic depends on its cost-effectiveness which require further investigation. Nonetheless, allowing physicians to select medications for individuals based on genetic factors that predispose to treatment response rather than on a trial and error basis via less precise non-personalized treatment may ultimately improve successful smoking cessation rates (Sturgess et al., 2011). In the post-GWAS era, translational research from several disciplines, including behavioral science, ethics and economics, should be performed in parallel with ongoing genetic studies for smoking pharmacogenetic trials. This would be a critical step to enable implementation of genetic insights into routine clinical practice in order to reduce the global health burden of smoking (Furberg et al., 2010).

Our paper is devoted to addressing the knowledge gap concerning cost-effectiveness of personalized medicine treatment in smoking cessation. More specifically, we explore, under the same cost, what outcome differences are between personalized treatment and non-personalized treatments. To undertake this task, we develop a lifecycle model in which key decisions on smoking, health and savings as well as life expectancy are all endogenously determined. We take into account the three main types of costs of smoking as in the literature. On the one hand, smoking accelerates health depreciation, thereby increasing demand for medical care (healthcare cost) and reduces labor income (morbidity cost). On the other hand, worse health results in lower life expectancy (mortality cost).

The main advantage of our approach for policy analysis is that we take into account individuals' endogenous response in a dynamic lifecycle setting. Moreover, individuals are allowed to be heterogeneous in their genotypes as newly advanced in the medical literature. Recent work shows that effects of cessation pharmacotherapy vary with haplotypes in the CHRNA5 nicotinic receptor gene. Three common haplotypes span the CHRNA5 gene region (H1: 25\%; H2: 44\%; H3: 31\%). Using data from smoking cessation trials conducted at the University of Wisconsin Transdisciplinary Tobacco Use Research Center (UW-TTURC), Chen et al. (2012) identified the usefulness of CHRNA5 genetic markers in predicting both cessation difficulty and treatment response (results replicated by Bergen et al., 2013). While the high-risk haplotype (H3) is unequivocally associated

\footnotetext{
${ }^{4}$ Increasing evidence suggests that the risk-benefit ratio of the medication can also vary with a person's genetic background (Green and Guyer, 2011).
} 
with heavy smoking and most difficulty in smoking cessation, smokers of this type respond well to medication. In contrast, smokers with the low-risk haplotype (H1), though smoke less on average and are more likely to quit with counseling, do not benefit from medication. Demographics are also found to affect smoking behavior (see a critical review by Chaloupka and Warner, 2000). More specifically, male smokers typically smoke more cigarettes per day than women, and male demand for cigarettes tends to be more price elastic than is female demand (Giovino et al., 1994; Chaloupka, 1990; Chaloupka and Grossman, 1996). Blacks are less likely to smoke and smoke less than whites (Chaloupka and Grossman, 1996). Research has also shown a substantially positive effect of education on health (Kenkel, 1991; Grossman and Kaestner, 1997; Lleras-Muney, 2005) and higher educated smokers are more likely to quit smoking (Chaloupkia, 1991). Finally, age is positively related to the number of cigarettes consumed per day (Giovino et al., 1994). As such, our paper incorporates three important dimensions of demographics, namely, gender, race and education. This integrated framework thereby enables a thorough study of rich dynamic interactions between consumption-saving, health investment and smoking, where individuals' lifecycle profiles depend critically on their demographics as well as genotypes. Under this setting, we can then evaluate various smoking cessation policies by aggregating individual-specific effects in a systematic manner.

We then calibrate our model to fit key observations from the U.S. data. The set of targets includes economics data such as income, various expenditure ratios, and life expectancy. It also constitutes some medical experiment data such as gene-dependent smoking by Chen et al. (2012) and differential gains in life years from smoking cessation by Jha, et al. (2013). Our calibrated model predicts well that life expectancy of smokers is 11-12 years shorter than nonsmokers and that the high-risk H3-type smokers live slightly shorter than other types, consistent with medical evidence. Our computed potential gain in life years for smokers quitting successfully at age 35 is the largest for H3 smokers (9.0 years), compared to 7.6 and 8.2 years for H1 and H2 genotypes, respectively. We also show that over their life course successful quitters have a slower rate of health deterioration, with more moderate health deterioration for white males with college degree, due to a stronger income effect associated with the more luxurious health good.

We then propose four separate measures of effectiveness for three smoking cessation policies with the same program costs, two with standard and one with personalized treatments. The first two measures are the policy coverage rates given the same budget and the resulting quit rates. The third is Consumption Equivalent of a covered smoker, which is the percentage increase in consumption 
(at each point in time) that is needed, while fixing everything else unchanged, to reach a certain level of lifetime utility. The last is Income Equivalent of a covered smoker, defined in the same way but in terms of the percentage increase in labor income. These equivalent measures have taken into account all private benefits and costs associated with participation in a program. We further construct three unified measures, including an expected Consumption Equivalent measure of a smoker, an expected Income Equivalent measure and a cost/effectiveness ratio based on expected Income Equivalent of a smoker. We find that, under the same program costs, personalized treatment provides coverages for more and maintains high effectiveness. For each dollar of the program cost, it generates 8.94 Income Equivalent in effectiveness, 22 - 45\% higher than the comparable figures under standard treatments. That is, personalized treatment is the most cost-effective in smoking cessation.

We would like to note that our lifecycle setting captures the spirits of two separate strands of literature. ${ }^{5}$ One strand is on health capital, building on the pivotal work by Grossman (1972a,b). Another is on health and life expectancy, pioneered by Rosen (1988) and Ehrlich and Chuma (1990). Our model is much richer not only because we endogenize consumption-saving, health investment, smoking and life expectancy, but also because we permit multi-dimensional heterogeneities. Our effectiveness measures are more general than quality adjusted life years (QALYs) commonly used in the literature of medicine and health (e.g., see the guidelines provided by Gold et al., 1996). Specifically, our lifetime utility based effectiveness measures account for time discounting, diminishing marginal valuation and differential utility weights. More importantly, our measures incorporate heterogeneous individuals' dynamic responses that enable us to capture different responses across different individuals at different ages over their life course. Our framework is ready to be applied to studying other types of addictive behavior, such as alcohol and illicit drugs. It can also be easily modified for evaluating other types of precision medicine in treating various diseases.

\section{$2 \quad$ The Model}

To properly model smoking behavior and its health consequences over an individual's life course, we develop a lifecycle framework with endogenously determined life expectancy. In contrast with

\footnotetext{
${ }^{5}$ The reader is referred to the handbook chapter by Chaloupka and Warner (2000) for a large body of empirical literature on smoking behavior and the effects of smoking policy (e.g., cigarette taxes and smoking ban), beyond those relevant studies to our paper cited above.
} 
many previous studies on endogenous life expectancy where health or life protection simply reduces mortality (e.g., Rosen, 1988; Ehrlich, 2000; Ehrlich and Yin, 2005; Jones, 2016), we allow better health to improve the quality of life and hence lifetime utility (in line with Ehrlich and Chuma, 1990; Chakraborty, 2004; Murphy and Topel, 2006; Hall and Jones, 2007; Chen, 2010). This addition is important because QALYs is a standard effectiveness measure in cost-effectiveness analysis in medicine and health. Following the health capital literature pioneered by Grossman (1972a,b), we allow health capital to evolve endogenously over time. While smoking can be enjoyable to an addict, it has a detrimental consequence for health by accelerating health deterioration. Departing from the literature, we consider heterogeneity in individuals' tastes for smoking. This is consistent with the medical literature that has identified genetic markers associated with smoking behavior (Tobacco and Genetics Consortium, 2010; Chen et al., 2016; Chen et al., 2015a; Chen et al., 2015b). Such a consideration is essential because it permits us to evaluate precision medicine with personalized treatments based on an individual's unique characteristics. Individuals are also heterogeneous in work efficiency and hence their labor income. Preference and income heterogeneities subsequently affect their differential smoking behavior, health capital and life expectancy.

\subsection{Model setup}

Time is continuous. An individual's life starts at $t_{0}$ when she acts as a decision-maker (who may be referred to as a young adult). Her life ends at $T$ which is endogenous and will be discussed later.

Throughout her life course $\left[t_{0}, T\right]$, she values consumption $c$ and health $h$ and may also value smoking $s$ depending on her genotypes. The flow utility accrued at time $t \in\left[t_{0}, T\right]$ from such enjoyment is assumed to take a simple log linear form:

$$
u(c, s, h, t)=\ln (c(t))+\alpha \ln (s(t))+\beta \ln (h(t))
$$

where $\alpha \geq 0$ and $\beta>0$ measure her preferences for smoking and health relative to general consumption. Importantly, individuals with different genetic markers will have different values of $\alpha$, which will be further elaborated when we conduct calibration analysis to fit the model with the data. As to be seen below, we will model the evolution of both nonhuman wealth and health capital as well as the wage-tenure profile. Thus, to avoid further complication, we elect not to include the habits of addiction stock in the utility function. ${ }^{6}$

\footnotetext{
${ }^{6}$ The reader is referred to Becker and Murphy (1988) for developing a habit-based rational addiction framework. This literature generates valuable insights including better understanding of the short versus long run price elasticity
} 
Letting $\rho$ be the subjective time discount rate, we can then write one's lifetime utility as:

$$
U=\int_{t_{0}}^{T} e^{-\rho\left(t-t_{0}\right)}[\ln (c(t))+\alpha \ln (s(t))+\beta \ln (h(t))] d t
$$

where we have plugged in the flow utility function given in (1). Thus, health raises an individual's lifetime utility via two channels: higher quality of life (through $\beta \ln (h(t)))$ and longer life expectancy (through $T$ ).

Two remarks are in order. First, in order for longevity to raise lifetime utility, it is necessary to ensure the flow utility to be positive. Given the log functional form, this is met when we choose the scale of health and income properly so that their logged values are sufficiently greater than zero (to be further elaborated in Section 3.1 below). This strategy in essence follows Murphy and Topel (2006), by assuming consumption bundles to be above their "subsistence" levels (which are, in our case, $c=h=1$ and $s=1$ for smokers with $\alpha>0) .{ }^{7}$ Second, although consumption and health has the same income elasticity under the simple log functional form, the positive health effect on life expectancy makes health a luxury good relative to consumption, which is consistent with the literature on health and life (Hall and Jones, 2007; Jones, 2016).

Consider now an individual with work efficiency $\theta$, facing a market wage in efficiency unit denoted by $w$ (needless to say, all dollar measures are in real terms). In addition to her work efficiency, her flow labor income at time $t$ depends critically on her labor market experience as well as her health status. While the former is standard in the labor economics literature, the latter captures the labor productivity effect of health emphasized by Grossman (1972b). Regarding these as two additive components of human capital, we can now specify the labor income obtained by an individual with work efficiency $\theta$ as:

$$
y(t)=\theta w(t)\left[h(t)+\kappa\left(e^{\phi\left(t-t_{0}\right)}-1\right)\right]
$$

In this formulation, we conveniently align the measurement of human capital with health capital, so $\kappa>0$ captures the relative importance of experience in labor income generation. Moreover, the paof addictive consumption demand, albeiting potential bias due to endogenous response in smoking intensity, as elaborated by Adda and Cornaglia, 2006. It is nonetheless beyond the scope of our paper.

${ }^{7}$ One alternative is to follow Hall and Jones (2007) and Jones (2016) to add a constant $\bar{u}>0$ in flow utility to ensure positive values. Another is to add a constant to the log function such as:

$$
u=\ln (1+c(t))+\alpha \ln (1+s(t))+\beta \ln (1+h(t))
$$

The latter setup would, however, generate extra income effects on smoking which is inconsistent with the empirical evidence (Chaloupka and Warner, 2000). 
rameter $\phi>0$ measures the return to experience and $\kappa\left(e^{\phi\left(t-t_{0}\right)}-1\right)$ captures the experience-driven wage-tenure profile that is equal to zero at time $t_{0}$ (when the individual is fully inexperienced). Note that $\theta$ takes different values for individuals with different gender, race and levels of education. Thus, although we refer to an individual as "she" for convenience, we do allow for gender differences in earning as observed in the real world.

In addition to labor income, an individual can also earn income from savings, which is in forms of holding an asset $a$ that provides a yield at the market (real) interest rate $r$. In each point in time, her flow (labor and interest) income is allocated to consumption, cigarette purchase and health-related spending that will be referred to as health investment $x$. Given the price per unit amount of smoking $p$, an individual's asset accumulation over her life course is governed by,

$$
\dot{a}=r(t) a(t)+y(t)-c(t)-p(t) s(t)-x(t)
$$

where $\dot{a} \equiv d a / d t$ and labor income is given by (3). That is, asset is accumulated when flow income $(r a+y)$ exceeds flow expenditure $(c+p s+x)$.

We next turn to the evolution of health capital where we highlight three important features. First, health can be improved with more investment in health, but such improvement is subject to diminishing returns. More specifically, given the current state of health $h$, health improvement measured by $\dot{h} \equiv d h / d t$ rises less than proportionately with either the current health status $(h)$ or health investment per unit of health capital $(x / h)$. Second, the health deterioration rate rises with the amount of smoking $(s)$ but falls with the current health status. Third, the smoking effect on the health deterioration rate is rising with age, as documented in medical studies such as Jha et al. (2013). To fulfill all these features, we propose the following health evolution process:

$$
\dot{h}=\left[\Phi x(t)^{\epsilon}-(\delta+\gamma(t) s(t))\right] h(t)^{\mu}
$$

We now check the required properties. The benefit of health investment is $\Phi x^{\epsilon} h^{\mu}=\Phi(x / h)^{\epsilon} h^{\mu+\epsilon}$, where $\Phi>0$ measures the extent to which health investment benefits health. To have diminishing returns in the beneficial effects of current health and health investment per unit of health capital on future health evolution, it is required that $\epsilon>0, \mu>0$ and $0<\mu+\epsilon<1$. We then examine the health deterioration rate, measured by $\left[(\delta+\gamma(t) s) h^{\mu}\right] / h$, where $\delta>0$ is the natural health deterioration rate. Thus, the health deterioration rate rises with smoking and falls with the current health status (because $\mu<1$ ), without additional assumptions. In order for the smoking effect on the health deterioration rate to rise with age, we further restrict that $\gamma(t)$ is an increasing function of 
$t$. In summary, under these parametric assumptions, the above functional form offers a parsimonious setting that governs the evolution of health capital satisfying all the required properties.

Finally, the individual dies when her health reaches a threshold level $\underline{h}$. That is, the terminal date of one's life $T$ is reached when $h \leq \underline{h}$. This setting is natural based on the medical literature, where $\underline{h}$ may be viewed as the biological requirement for a human body to function. Because the evolution of an individual's health capital depends on her decisions, her life expectancy is thereby endogenous depending particularly on smoking behavior and health investment. Thus, our framework is in spirit consistent with health capital model of Grossman (1972a,b) and the endogenous life expectancy model of Rosen (1988) in which the value of saving a current life is the expected present value of consumer surplus at that age.

The dynamic optimization problem can therefore be divided into two steps. In the first step, we view the terminal date $T$ as given. We then solve the lifecycle model in which an individual of type $(\alpha, \theta)$ decides on consumption/saving, smoking, and health investment, all as functions of $T$, to maximize her lifetime utility given by (2) subject to asset accumulation and health capital evolution equations (4) and (5). In the second step, we substitute the smoking and health investment functions obtained in the first step, denoted $S(t, T)$ and $X(t, T)$, into (5) to generate the path of health capital, denoted $H(t, T)$. Then we pin down life expectancy by solving

$$
H(T, T)=\underline{h}
$$

\subsection{Model characterization}

To solve the dynamic optimization problem, we set up the current-value Hamiltonian for each given value of life expectancy $T$ :

$$
\begin{aligned}
\mathcal{H}(c, s, x, t)= & \ln (c)+\alpha \ln (s)+\beta \ln (h) \\
& +\lambda_{1}\left\{r a+\theta w\left[h+\kappa\left(e^{\phi\left(t-t_{0}\right)}-1\right)\right]-c-p s-x\right\} \\
& +\lambda_{2}\left\{\left[\Phi x^{\epsilon}-(\delta+\gamma(t) s)\right] h(t)^{\mu}\right\}
\end{aligned}
$$

where $\lambda_{1}$ and $\lambda_{2}$ are the costate variables associated with asset accumulation and health capital evolution equations (4) and (5). For the remainder of the paper, we will suppress time index $t$ whenever it does not cause any confusion.

Applying Pontryagin Maximum Principle in optimal control theory, we can obtain three firstorder conditions with respect to $c, s$ and $x$, and two Euler equations with respect to $a$ and $h$. 
Straightforward manipulation of these five equations to eliminate the two costate variables leads to the following conditions for the dynamic optimization problem:

$$
\begin{gathered}
\frac{s}{c}=\frac{\alpha}{p+\gamma(t) /\left(\Phi \epsilon x^{\epsilon-1}\right)} \\
\frac{\dot{c}}{c}=r-\rho \\
(1-\epsilon) \frac{\dot{x}}{x}=r-\Phi \epsilon x^{\epsilon-1} h^{\mu}\left(\frac{\beta c}{h}+\theta w\right)
\end{gathered}
$$

Equation (8) indicates that smoking relative to consumption increases with the taste for smoking $(\alpha)$, but decreases with the price of cigarettes $(p)$ and its (relative) health cost $\left(\gamma(t) /\left(\Phi \epsilon x^{\epsilon-1}\right)\right)$. When medical treatment cannot effectively mitigate the detrimental effect of smoking on health (i.e., when $\Phi$ is low), it is optimal for an addict to reduce or even quit smoking because her utility enjoyment is outweighed by her health deterioration. Similarly, a rising health cost of smoking as a result of higher medical spending (i.e., higher $x$ ) also discourages smoking.

Equation (9) is standard in dynamic economic models. It governs the dynamic path of consumption: consumption grows when the rate of return on saving exceeds the subject rate of time discounting. Typically, consumption is expected to grow (that is, $r>\rho$ ). Equation (10) governs the dynamic path of health investment. To gain insight from this complicated expression, we note that biological limitation implies health capital deterioration when an individual is sufficiently old. Thus, the consumption-health capital ratio is expected to increase at least for older individuals. This implies that, from (10), health investment is likely to decrease eventually when approaching to the end of lifetime, which is consistent with diminishing returns in health investment and biological limitation of its effect on health capital.

Although we cannot solve analytically the entire dynamic paths of consumption, smoking, health investment, health capital and assets, the three expressions above, (8)-(10), together with the two evolution equations, (4) and (5), and the boundary condition (6) can be used to solve numerically the five dynamic paths, $\{c(t), s(t), x(t), a(t), h(t)\}_{t=t_{0}}^{T}$, and the endogenous life expectancy, $T$. To do so, however, we must first calibrate the model to fit the data to which we now turn. 


\section{$3 \quad$ Calibration and Numerical Solution}

We are now prepared to calibrate the model to fit the data. Once this task is completed, we can then use the quantitative model to evaluate various policies on smoking cessation.

Our calibration exercises consist of three steps. In the first step, we calibrate all parameters for a representative individual, who may be regarded as the average individual. In the second step, we allow heterogeneity in preferences for smoking: for nonsmokers, we set $\alpha=0$; for smokers, we calibrate the three $\alpha$ 's for smokers with three genotypes associated with smoking addiction. In the third step, we allow heterogeneity in work efficiency to calibrate $\theta$ 's for individuals in different demographic groups.

We discretize the life span so that one year corresponds to one period of time, and assume life starts at 18 years old (i.e., $\left.t_{0}=18\right) .^{8}$

\subsection{Step 1: Calibration to fit the average}

In the first step, we assume that individuals are homogeneous in all aspects so we have a single value for $(\alpha, \theta)$, which allows us to calibrate all the common parameters to fit the average of each of the targeted data.

There are eleven parameters, $\rho, \alpha, \beta, \Phi, \epsilon, \delta, \mu, \theta, \phi, \kappa$, and $\underline{h}$, and one functional form, $\gamma(t)$, to be determined. Given homogeneous work efficiency, we conveniently normalize $\theta w$ to be one. We preset the subjective time discounting rate as $\rho=0.02$, compromising the economics and the health and medicine literature. Then the growth rate of consumption $(g)$ is set to equal that of output per capita in the US (1.8\%), so the real interest rate becomes $r=\rho+g=0.038$. We assume initial wealth to be $a_{0}=0$, which is inconsequential for the cost-effectiveness analysis conducted in the paper.

We choose the curvature of the health evolution function with respect the current health status to be $\mu=0.05$. Such sufficiently large diminishing return in health is to ensure a reasonable health evolution path to generate an interior solution for life expectancy, an issue to address with endogenous lifetime. We then normalize the threshold health level at death to be $\underline{h}=1$ and set the initial stock of health at age 18 as $h_{0}=100$. These provide natural boundaries of the health stock within which the dynamic path of health can be computed to fit real world data. To align

\footnotetext{
${ }^{8}$ One may easily allow $t_{0}$ to be lower and adjust the experience accumulation formulation in (3) if teenager smoking behavior is a major research focus.
} 
health-based and experience-based human capital, we also set the scaling parameter for experience as $\kappa=100$. The scale of normalization of $h_{0}$ and $\kappa$ not only ensures that the flow utility for a living person is positive for all demographic and genotypes, but also yields reasonable values of a statistical life (VSL) of a smoker or a nonsmoker (to be elaborated in Section 4.1 below).

In the labor economics literature, the wage-tenure profile estimation usually yields an experience return at $3-5 \%$. We thus take the average to set $\phi=0.04$. Consider that a nonsmoker who never invests in health over the entire life course (i.e., $x=0$ for all $t$ ) would live for 50 years. This yields a natural health deterioration rate at $\delta=2.602$. To be consistent with medical evidence that smoking cessation at different ages has different impact on life expectancy (Jha et al., 2013), we specify $\gamma(t)$ as a step function:

$$
\gamma(t)=\left\{\begin{array}{l}
\gamma_{0} \text { for } t \leq 30 \\
\gamma_{1} \text { for } 31 \leq t \leq 40 \\
\gamma_{2} \text { for } t \geq 41
\end{array}\right.
$$

where the three $\gamma$ 's are yet to be determined.

Thus, the main parameters that remain to be calibrated are related to preference, $\alpha, \beta$, and to the effectiveness of health investment, $\Phi$ and $\epsilon$, together with three $\gamma$ 's related to the age-dependent consequences of smoking for health. These 7 parameters are calibrated based on 3 targeted ratios, the average life expectancy, plus 3 age-dependent incremental life saving figures as a result of smoking cessation.

The three targeted ratios are: (i) the consumption-to-output ratio $\left(\frac{c}{y}\right)$, (ii) the tobacco-expenditureto-output ratio $\left(\frac{p s}{y}\right)$, (iii) the health-investment-to-output ratio $\left(\frac{x}{y}\right)$, based on the U.S. data averaged across individuals and over time. Using data from Penn World Table 6.3 (1998-2007, US average), we compute $\frac{c}{y}=0.7$. We measure health investment by medical expenditure. Using data from Panel Study of Income Dynamics (PSID) 1999-2011, we measure the health-investment-tooutput ratio $\frac{x}{y}$ as an average household's total medical expenditure to total labor income ratio. ${ }^{9}$ This gives $\frac{x}{y}=0.051$. That is, an average individual (weighted average of addicts and nonaddicts) invests about $5 \%$ of her income in health. Also using the same waves of PSID data, we compute the

\footnotetext{
${ }^{9}$ The PSID data has contained information of medical expenditure since the year 1999, and the interval between every two surveys is 2 years. Hence, our dataset includes 7 surveys from 1999 to 2011 . Note that each survey includes information for the year before the survey year. Notably, labor income excludes farm and unincorporated business income. Also, in computing the average, observations with $\frac{x}{y}$ ratio exceeding one or negative are excluded from the sample.
} 
tobacco-expenditure-to-output ratio $\frac{p s}{y}$ as an average household head's total smoking expenditure over total labor income. ${ }^{10}$ More specifically, smoking expenditure $p s$ is computed by multiplying price of per pack of cigarettes (normalize cigarette price in 2009 to be one and compute price in other years correspondingly with CPI adjusted, which results in the average price during 1998-2010 0.73 per pack), cigarettes per day from PSID, and 365 days. We get $\frac{p s}{y}=0.019$. That is, an average individual (weighted average of addicts and nonaddicts) spends about $2 \%$ of her income on smoking.

The average life expectancy of the US population is 78 years old, based on the World Bank data (1998-2011). From Jha et al. (2013), the averaged increases in life expectancy for smokers who quits at the age 30,40 , or 50 are 10, 9, and 6 years, respectively.

The algorithm for calibrating these parameters are given as follows. We first choose a set of values for the parameters (initial guesses), and then solve the model which results in a set of lifecycle decisions and outcomes for a representative individual. Then we compute the model solutions of the targets and compare them to the corresponding targeted values. If they are not close enough, we revise the guesses based on insights from model characterization. We repeat doing this until the model solutions and the target values are sufficiently close. From our result, while all the targeted ratios and life expectancy are matched very well, the increases of life expectancy for a representative smoker who quits at the age 30,40 , or 50 turn out to be 10,8 , and 6 years, which are close enough to the targeted results of 10,9 , and 6 years.

\subsection{Step 2: Heterogeneous preferences for smoking}

In the second step, we allow for heterogeneity in preferences for smoking in order to capture different genotypes associated with smoking addiction.

In particular, we calibrate the three $\alpha$ 's for smokers with three genotypes, H1, H2, and H3, while employing all other parameter values from the first step. We use cigarettes per day (CPD) for three types of smokers and shares of each type from Chen et al. (2012), rescaling the amount of smoking to fit the model units which becomes our targeted value of smoking $(s)$ for each genotype. Again, we conduct this task using the guessing-revising-converging algorithm. We obtain $\alpha_{1}=0.209$, $\alpha_{2}=0.212$, and $\alpha_{3}=0.238$, corresponding to $\mathrm{H} 1, \mathrm{H} 2$, and $\mathrm{H} 3$ types of smokers respectively. Of course, once a smoker quits smoking successfully, $\alpha$ is set to be zero and their preference for smoking

\footnotetext{
${ }^{10}$ Again, in computing the average, observations with $\frac{p s}{y}$ ratio greater than one or negative are excluded from the sample.
} 
is regarded the same as nonsmokers. Table 1 summarizes all the calibrated parameter values under $\theta w=1$.

We are now prepared for utilizing the calibrated model to compute lifecycle profile for the three types of smokers and compare it with nonsmokers. Table 2 presents such comparison in key indicators including life expectancy $T$, the consumption ratio $\frac{c}{y}$, the smoking expenditure ratio $\frac{p s}{y}$, and the medical expenditure ratio $\frac{x}{y}$ for each of the four groups of population, as well as the respective population weighted averages.

Table 1. Parametrization of the model

\begin{tabular}{|l|l|l|}
\hline \multicolumn{1}{|c|}{ parameter } & \multicolumn{1}{c|}{ value } & \multicolumn{1}{c|}{ target } \\
\hline subjective time discounting & $\rho=0.020$ & literature \\
\hline health stock boundaries & $h_{0}=100, \underline{h}=1$ & normalized \\
\hline experience scaling factor & $\kappa=100$ & normalized \\
\hline experience return & $\phi=0.040$ & literature \\
\hline initial wealth & $a_{0}=0$ & preset \\
\hline health curvature & $\mu=0.05$ & preset \\
\hline natural health deterioration rate & $\delta=2.602$ & computed \\
\hline health cost of smoking & $\gamma_{0}=0$ & $\begin{array}{l}\text { joint targets of } \frac{c}{y}, \frac{p s}{y}, \frac{x}{y}, T, \text { plus } \\
\text { incremental life saving for quitting } \\
\text { smoke at age } 30,40, \text { or } 50\end{array}$ \\
\hline preference for health quality & $\beta=0.029$ & same as above \\
\hline health investment efficacy & $\Phi=0.359$ & same as above \\
\hline health investment curvature & $\epsilon=0.448$ & same as above \\
\hline H1 & $\gamma_{1}=0.209$ & $\alpha_{2}=0.212$ \\
tastes for smoking for H2 & $\alpha_{3}=0.238$ & same as above, plus CPD \\
\hline
\end{tabular}

As can be seen, life expectancy of smokers is between 11 to 12 years shorter than nonsmokers, consistent with medical evidence (11 years for women and 12 year for men, based on Jha et al., 2013). Moreover, H3-type smokers live slightly shorter than other types, matching with medical evidence that CHRNA5 is associated with increased mortality in large-scale population studies 
(Kupiainen et al., 2016; Hallden, et al., 2015). Smokers spend a lower proportion of income on normal consumption goods but about 10 percent of income on tobacco; they also incur a larger medical expenditure relative to income.

The medical expenditure ratio may look too low for nonsmokers compared smokers, which deserves further discussion. We first note that life expectancy of nonsmokers is above 11 years longer than smokers and that health investment is declining toward the end of life when diminishing returns are kicking in. This lowers the average medical expenditure ratio of nonsmokers over their longer life span. If we trim everyone's life span to the be the same as the type with the shortest life (i.e., H3-type smokers), then the $\frac{x}{y}$ ratios become very close for all types ( 0.073 for smokers and 0.072 for nonsmokers). More importantly, so far we assume work efficiency $(\theta)$ is the same for individuals, while in the real world it is larger for nonsmokers than for smokers. When we allow for heterogeneity of $\theta$ for smokers and nonsmokers (i.e., 0.93 versus 1.03, computed from PSID) and trim life span to be the same as H3 smokers, the $\frac{x}{y}$ ratios are 0.071 and 0.074 for smokers and nonsmokers, respectively. With this node, we now turn to step 3 to calibrate differentiated $\theta$ 's for individuals in different groups. Due to different smoking behaviors and health evolution paths, this issue is naturally resolved.

Table 2. Lifecycle comparison

\begin{tabular}{|l|l|l|l|l|l|}
\hline & $\mathrm{H} 1$ & $\mathrm{H} 2$ & $\mathrm{H} 3$ & $\mathrm{~N}$ & mean \\
\hline share of population $(\%)$ & 6 & 10 & 8 & 76 & \\
\hline life expectancy $T$ & 70 & 70 & 69 & 81 & 78.3 \\
\hline consumption ratio $\frac{c}{y}$ & 0.66 & 0.65 & 0.65 & 0.71 & 0.70 \\
\hline smoking expenditure ratio $\frac{p s}{y}$ & 0.10 & 0.10 & 0.11 & 0.00 & 0.02 \\
\hline health investment expenditure ratio $\frac{x}{y}$ & 0.070 & 0.070 & 0.073 & 0.045 & 0.051 \\
\hline
\end{tabular}

\subsection{Step 3: Heterogeneous work efficiency}

Later, we allow individuals' work efficiency to differ by gender, race and education. Normalizing now the market wage in efficiency unit as one $(w=1)$, we now calibrate different values of $\theta$ for each group. By construction, the population weighted average of $\theta$ must be one. Thus, $\theta$ is indeed a relative work efficiency measure (relative to the mean).

Specifically, let the gender indicator be $M$ ( $=1$ for male and 0 for female), the race indicator be $W(=1$ for white and 0 for black), and the education indicator be $C$ ( $=1$ for college degree and 
0 for no college degree). We then categorize all individuals into 8 (i.e., $2 \times 2 \times 2$ ) groups. We calibrate $\theta$ 's of the eight cells of population by gender, race and education using PSID labor income of individuals (household head) aged between 23 and 26, normalized to an average of one. We pick this age range for three reasons. First, the vast majority of people have completed education and started working by 23. Second, their health may have not been significantly affected by smoking behavior by 26. Third, the experience may have not contributed much to their labor income.

In Table 3, we report the population share of each group among smokers based on PSID data and the calibrated value of $\theta$ for each group.

Table 3. Work efficiency

\begin{tabular}{|c|c|c|c|c|}
\hline$M$ & $W$ & $C$ & population share (\%) & work efficiency $\theta$ \\
\hline 0 & 0 & 0 & 5 & 0.64 \\
\hline 0 & 1 & 0 & 45 & 0.79 \\
\hline 0 & 0 & 1 & 0 & 1.14 \\
\hline 0 & 1 & 1 & 5 & 1.11 \\
\hline 1 & 0 & 0 & 7 & 0.73 \\
\hline 1 & 1 & 0 & 34 & 1.11 \\
\hline 1 & 0 & 1 & 1 & 1.33 \\
\hline 1 & 1 & 1 & 3 & 1.48 \\
\hline
\end{tabular}

As can be seen, college educated all have higher than the mean work efficiency and are thus expected to have higher labor income upon controlling the age. Black with no college degree, on the contrary, have much lower work efficiency and hence lower labor income within the same age cohort. In addition, there is a gender gap that leads to higher labor income for males compared to females. Such gaps are larger for white than for black. All these implied patterns for labor income are consistent with the labor economics literature. As well documented in the literature, better educated earn higher labor income, have better health knowledge, invest more in health for longevity and are less likely to be smokers (Chaloupkia, 1991; Kenkel, 1991; Grossman and Kaestner, 1997; Lleras-Muney, 2005). As a consequence, this dimension of heterogeneity can lead to an outcome with nonsmokers having larger health investment relative to income.

In addition, it is noted from medical evidence (Chen et al., 2012) that the share of three genotypes does not vary significantly across gender or education groups, but does vary much across 
racial groups. In particular, whites have a much larger share of H3 type than blacks (35\% versus $6 \%$ ), and blacks have a much larger share of $\mathrm{H} 1$ type than whites (51\% versus $21 \%$ ), while the share of $\mathrm{H} 2$ type is similar for whites and blacks. This heterogeneity in shares of genotypes will cause differences in policy effects for different racial groups as will be analyzed later.

\section{$4 \quad$ Policy Evaluations}

With the theoretical model calibrated to fit the data, we have a running numerical model that can be readily used for policy evaluation. In the interest of this study, we focus on evaluating smoking-cessation policy contrasting personalized with standard medications for smoking-cessation treatment. By doing so, we establish an integrated dynamic framework for a systematic costeffectiveness analysis on precision medicine in this regard.

\subsection{Method}

We conduct the analysis by comparing the effectiveness of the following three government policies including two types of standard medication policies $\left(\boldsymbol{S}, \boldsymbol{S}^{\prime}\right)$ and one personalized medication policy $(\boldsymbol{P})$, all under the same budgetary cost. Thus, whichever policy yielding greater value of effectiveness is by construction more cost-effective. The three smoking cessation policies are specified as follows.

1. S: subsidize $10 \%$ of smokers randomly with a $\$ 600$ voucher for both counseling and medication treatment, regardless of genotypes.

2. $\mathbf{S}^{\prime}$ : subsidize $10 \%$ of smokers randomly with two types of vouchers: a $\$ 150$ voucher for counseling treatment only, given to $5 \%$ of smokers, and a $\$ 1050$ voucher for both counseling and medication treatment, given to another $5 \%$ of smokers, regardless of genotypes.

3. P: offer rebate to $n \%$ of smokers who have taken gene test to identify their genotypes associated with smoking addiction. The rebate consists of three parts. $R 1$ : $\$ 96$ for gene test; R2: $\$ 72$ for counseling; R3: $\$ 432$ for medication. All subsidized smokers receive $R 1$ and $R 2$, but only those identified as $\mathrm{H} 2$ and $\mathrm{H} 3$ genotypes receive $R 3$. The percentage of smokers that are subsidized, $n$, is determined such that the total budget is identical to that under $\boldsymbol{S}$ and $S^{\prime}$. 
Several important points regarding the design of the policies above are in order.

First, the size of the subsidy in the benchmark case under policy $\boldsymbol{S}$ ( $\$ 600$ per person) is reasonable for covering about half of counseling and medication treatment cost (see the detailed breakdown below). The amount (inflation-adjusted) is comparable to the financial incentives (\$500) provided for smoking cessation in the randomized controlled trial conducted by Volpp et al. (2009) - their study finds that smokers receiving financial incentives are significantly more likely to participate in and complete a smoking-cessation program.

Second, the size of the budget regarding $10 \%$ coverage of smokers in the benchmark case under policy $\boldsymbol{S}$ is also reasonable. ${ }^{11}$ The current policy is for Medicaid to pay for all smokers. Since Medicaid covers about $20 \%$ of the population, it is expected that more than $20 \%$ of smokers may use this benefit. Moreover, the amount of the subsidy is only about half of the actual treatment cost incurred. Even by assuming that only a quarter of Medicaid eligible smokers take advantage of this benefit, the size of the budget under our experiment would not be higher than the budgetary cost of the current policy through Medicaid coverage for smoking cessation.

Third, the three policies are designed on a revenue-neutral base, meaning that the total budget is equalized across all three policies. The shares of three genotypes among smokers are $0.25,0.44$, and 0.31 for H1, H2, and H3 respectively (Chen et al., 2012; Bergen et al., 2013). This enables us to compute $n$ in the next subsection.

Fourth, the value of each type of voucher or rebate in policy $\boldsymbol{S}^{\prime}$ and $\boldsymbol{P}$ is based on the monetary cost of the corresponding treatment or test. We estimate the cost to be $\$ 150$ for counseling, $\$ 900$ for medication, and $\$ 200$ for a gene test. The counseling cost $(\$ 150)$ and the total cost of counseling and medication $(\$ 1,050)$ are the base for the vouchers in policy $\boldsymbol{S}^{\prime}$. The total cost of the three is $\$ 1,250$. Hence, in policy $\boldsymbol{P}$, the value of each type of rebate is proportional to the cost of the corresponding treatment or test.

Fifth, the motivation behind the policy design is as follows. Policy $\boldsymbol{S}$ is a proxy of the standard policy that recommends all smokers to receive both counseling and medication. Policy $\boldsymbol{S}^{\prime}$ is a proxy of the real world policy by which some smokers receives counseling while others also receive medication. Neither of the two standard policies takes smokers' genotypes into account. By contrast, policy $\boldsymbol{P}$ is personalized based on genotypes. Smokers receive subsidy only if they have taken a gene test, and only those with genotypes responsive to medication would receive subsidy for medication treatment.

\footnotetext{
${ }^{11}$ We could use other numbers without changing the main results of policy comparison.
} 
In our experiment, we carry out the policies on smokers aged 35 since medical research shows that smokers within age 30-40 gain larger health benefit from cessation than other age groups. We solve the model with each policy for each type of smokers with different genotypes and different work efficiency in the dimensions of gender (male versus. female), race (white versus. black), and education (college degree versus. no college degree). In addition, when modeling the cost of treatment or gene test, we also take into account the time cost (i.e., time needed for traveling, waiting, and receiving treatment) besides the monetary cost, and convert it into labor income using hourly wage of each group of population (again, using PSID data). Based on medical practice, we estimate that it takes about 9 hours to receive counseling, 7.5 hours for medication, and 2 hours for gene test.

Finally, we employ four measures for policy comparison:

1. Share of smokers that can be subsidized;

2. Quit rates of subsidized smokers;

3. Consumption Equivalent (CE) of subsidized smokers;

4. Income Equivalent (IE) of subsidized smokers.

While Measure 2 is standard, Measure 1 is an "extensive margin" that has often been overlooked in previous studies. The omission of this extensive margin effect would bias the cost-effectiveness analysis significantly, particularly because of the nature of personalized medical treatment. Measures 3 and 4 require further explanations.

Consumption Equivalent, or $C E$, is defined as the percentage increase in consumption (at each point in time) that is needed, while fixing everything else unchanged, to reach a certain level of lifetime utility if a policy covers the individual. Mathematically, $C E$ is determined by,

$$
\int_{t_{0}}^{T} e^{-\rho\left(t-t_{0}\right)}[\ln (c(1+C E))+\alpha \ln (s)+\beta \ln (h)] d t=\bar{U}
$$

where $\bar{U}$ is the lifetime utility when the individual is covered by a particular policy. Denote by $U_{0}$ the untreated lifetime utility in the absence of policy intervention:

$$
U_{0} \equiv \int_{t_{0}}^{T} e^{-\rho\left(t-t_{0}\right)}[\ln (c)+\alpha \ln (s)+\beta \ln (h)] d t
$$

Hence, we derive Consumption Equivalent as:

$$
C E=\exp \left[\frac{\rho\left(\bar{U}-U_{0}\right)}{1-e^{-\rho\left(T-t_{0}\right)}}\right]-1
$$


Note that $\bar{U}$ is expected utility taking into account the probabilities that smoking cessation may either succeed or fail under a policy. These probabilities vary across individuals, depending on genotypes, education, and the type of treatment. ${ }^{12}$

An alternative measure to $C E$ is Income Equivalent, or $I E$, which is defined as the percentage increase in income (at each point in time) that is needed to satisfy the consumption increase as defined in $C E$. Mathematically, $I E$ is determined by,

$$
\int_{t_{0}}^{T} e^{-r\left(t-t_{0}\right)}[c(1+C E)+x+p s] d t=\int_{t_{0}}^{T} e^{-r\left(t-t_{0}\right)} y(1+I E) d t
$$

Applying (14) and manipulating, we obtain:

$$
I E=C E \cdot \frac{\int_{t_{0}}^{T} e^{-r\left(t-t_{0}\right)} c d t}{\int_{t_{0}}^{T} e^{-r\left(t-t_{0}\right)} y d t}=\frac{\int_{t_{0}}^{T} e^{-r\left(t-t_{0}\right)} c d t}{\int_{t_{0}}^{T} e^{-r\left(t-t_{0}\right)} y d t}\left\{\exp \left[\frac{\rho\left(\bar{U}-U_{0}\right)}{1-e^{-\rho\left(T-t_{0}\right)}}\right]-1\right\}
$$

Intuitively, $C E$ and $I E$ represent the benefit of a policy to a smoker in terms of lifetime utility, measured as an equivalence of consumption or income increase. Since life expectancy varies across groups of smokers, $C E$ and $I E$ are life-expectancy-weighted to be comparable across individuals.

The measure of $I E$ is particularly useful for constructing a dollar measure of effectiveness as well as the value of a statistical life, VSL. By normalizing the value of death as zero (which can be simply obtained by setting $c=s=h=1$ for smokers and $c=h=1$ for nonsmokers, all at their subsistence levels), one may compute VSL as the dollar value of willingeness to pay for a living status on average. This is done by first computing $I E$ for bringing lifetime utility from zero to the calibrated value in the model of an adult. We can then multiply $I E$ by average income of an indivual to obtain a sollar measure. We finally convert permanent flow income at age 45 (average age of a licensed driver in the U.S. as we plan to compare our VSL with empirical estimates by Ashenfelter and Greenstone, 2004) to capitalized dollar value based on the real interest rate of $3.8 \%$ and the life expectancy of smokers and nonsmokers, respectively.

Specifically, the $I E$ 's for bringing lifetime utility of a smoker of type H1, H2 and H3 from zero to the calibrated benchmark value amount to a permanent flow income increase from $100 \%$ to $539.8 \%$, $541.1 \%$ and $578.0 \%$, respectively. Assume that an average smoker of any genotype has the same

\footnotetext{
${ }^{12}$ For $\mathrm{H} 1$ smokers, the quit rate is $58.6 \%$ for those with college degree, and $43.1 \%$ for non-college ones, regardless of the type of treatment. For H2 smokers, these two rates are $43.1 \%$ (college) and $30.8 \%$ (non-college) when receiving counseling only, and $61.3 \%$ (college) and $43.8 \%$ (non-college) when receiving counseling plus medication. For H3 smokers, these are $29.0 \%$ (college) and $20.7 \%$ (non-college) when receiving counseling only, and $61.3 \%$ (college) and $43.8 \%$ (non-college) when receiving both treatment (data from Chen et al., 2012).
} 
work efficiency $\theta=0.93$. In this case, a smoker's average income is 251 efficiency wage units or US $\$ 40,969$ at 2009 constant dollars and the respective life expectancies become 69, 68 and 68 years for the three genotypes. As a result, VSL's for type H1, H2 and H3 can be computed as 2.143, 2.129 and 2.160 million US dollars. Given the population weights for the three genotypes $(25 \%, 43 \%$ and $32 \%$ within smokers), the (weighted) average VSL of a smoker becomes 2.14 million US dollars. In the case of nonsmokers, the $I E$ for bringing lifetime utility from zero to the calibrated benchmark value equals a permanent flow income increase from $100 \%$ to $435.1 \%$. While work efficiency is 1.03 and average income is US\$61,304 (at 2009 constant dollars), the life expectancy is 81 . Accordingly, the VSL of a nonsmoker is computed as 3.23 million US dollars.

Given the population weights (6\% smokers of $\mathrm{H} 1$ type, $10.3 \%$ smokers of $\mathrm{H} 2$ type, $7.7 \%$ smokers of $\mathrm{H} 3$ type and $76 \%$ nonsmokers), the (weighted) average VSL in our model is equal to 2.97 million US dollars. In the empirical literature, Ashenfelter and Greenstone (2004) estimate an average US driver's VSL at 2.06 million dollars (CPI adjusted to 2009 constant dollars), whereas Costa and Kahn (2003) obtain an average prime age (18-30) US male's VSL as 6.97 million dollars (also CPI adjusted to 2009 constant dollars). Our average VSL figure thus falls in between of their estimates, which is viewed as empirically plausible. ${ }^{13}$

Notably, both $C E$ and $I E$ are measures of effectiveness. They are more general than the typical measure by QALYs in the literature of medicine and health. In contrast with QALYs, our lifetime utility based effectiveness measures account for time discounting and diminishing marginal valuation. Moreover, our measures consider differential utility weights that are calibrated to fit the data. Further, our measures incorporate heterogeneous individuals' dynamic responses. This is important because such responses varies across different individuals at different ages over their life course, as illustrated in the next subsection to which we now turn.

\subsection{Findings}

In this subsection, we begin by computing potential gains in life years for heterogeneous groups of smokers if cessation at 35 years old becomes successful and by contrasting the lifecycle profiles in smoking, health investment, health capital and labor income between a quitter and a nonquitter. We then conduct policy effectiveness analysis and report results from policy comparison using the four measures described in the previous subsection. All the averaged figures reported are based on

\footnotetext{
${ }^{13}$ We could adjust one of the scaling parameters, $h_{0}$ or $\kappa$, to match a particular estimate of VSL if it is so targeted. This is however not the focus of the paper.
} 
population weighted measures of the most disaggregated groups (demographics and biomarkers).

\subsubsection{Gains in life years}

Table 4 reports the potential gain in life years (LY) for smokers with the three genotypes and their average if cessation (at 35 years old) is successful.

Table 4. Gains in life years for three genotypes

\begin{tabular}{|l|c|}
\hline & gain in LY \\
\hline mean & 8.30 \\
\hline H1 & 7.61 \\
\hline H2 & 8.17 \\
\hline H3 & 9.04 \\
\hline
\end{tabular}

The results suggest that, across the three genotypes, the gain in LY is the largest for H3 smokers (9.04 years), followed by H2 (8.17 years) and then H1 (7.61 years). This result matches medical studies which find that the gain in life years would be higher for H3 smokers. This is because that (i) the risk in mortality is higher for $\mathrm{H} 3$ as a result of smoking, and (ii) H3 smokers are less able to quit, more likely to smoke longer or inhale more deeply, and more likely to have longer duration of smoking.

Table 5 shows life year gain for each of the 8 demographic groups (gender, race and education).

Table 5. Gain in life years for eight demographic groups

\begin{tabular}{|l|l|l|c|}
\hline $\mathrm{M}$ & $\mathrm{W}$ & $\mathrm{C}$ & gain in LY \\
\hline 0 & 0 & 0 & 5.00 \\
\hline 0 & 1 & 0 & 6.35 \\
\hline 0 & 0 & 1 & 10.92 \\
\hline 0 & 1 & 1 & 10.35 \\
\hline 1 & 0 & 0 & 5.57 \\
\hline 1 & 1 & 0 & 10.79 \\
\hline 1 & 0 & 1 & 13.06 \\
\hline 1 & 1 & 1 & 16.00 \\
\hline
\end{tabular}


Thus, across demographic groups, groups with larger work efficiency $\theta$ gain more from lengthening life expectancy by quitting smoking. This gain varies from 5 years for black, non-college, female smokers to 16 years for white, college, male smokers.

\subsubsection{Lifecycle profiles: quitters versus nonquitters}

We now contrast the lifecycle profiles between a quitter and a nonquitter. In particular, we consider the quitter as to successfully stop smoking at age 35. For illustrative purposes, we focus on two demographic groups:

1. white females with no college degree: this is the largest group of smokers (45\%), whose work efficiency is far below one (0.79) and potential gain in LY from quitting is low (6.35 years);

2. white males with college degree: this constitutes a small group (3\%) of smokers, but has the highest work efficiency (1.48) and the largest potential gain in LY from quitting (16 years), so informative for comparison purposes.

For both groups, we choose H2 genotype, which constitutes the largest fraction of smokers in both demographic groups.

In Figure 1, we plot the lifecycle profiles of the smoking expenditure ratio (top panels), the health investment expenditure ratio (middle panels) and health capital (bottom panels). Let look at the case of white females with no college degree (left panels). In our calibrated model, all nonquitters' smoking rises with age, consistent with evidence in the literature (Giovino et al., 1994; Chaloupka and Warner, 2000), though the smoking expenditure ratio declines with age. The zigzag pattern of the smoking expenditure ratio is due to the simple step function form to capture the rising effect of smoking on health (refer to the $\gamma(t)$ function given by (11) and the calibrated values reported in Table 1). While the white males with college degree have a similar lifecycle profile (right panels), their smoking expenditure ratios are lower after age 30 when the detrimental effect of smoking on health becomes larger to overcome the gender factor (males smoke more than females) and when their quitting attempts are relatively more resistant (this last point is not reflected in the figure, but can be shown with quit rates, which is $59 \%$ for white males with college degree versus $43 \%$ for white female with no college degree).

We turn next to the lifecycle profiles of the health investment expenditure ratio. While for all groups the health investment expenditure ratios decline over the lifecycle, that of nonquitters 
declines at a slower rate, suggesting a higher demand for investment in health by nonquitters. Moreover, throughout the life course, such ratios are larger to white males with college degree, compared to white females with no college degree. This is essentially due to the positive income effect: recall that the positive health effect on life expectancy under our utility function setting makes health a luxury good relative to consumption.

We at last examine the lifecycle profiles of health capital. Despite health investment, health naturally deteriorates since age 18. Not surprisingly, successful quitters at age 35 have a slower rate of health deterioration, whereas health deterioration is more moderate for white males with college degree due to their stronger incentives to invest in health as elaborated above.

\subsubsection{Policy Effectiveness}

We now report our main findings obtained by comparing the four key measures under the three proposed policies.

\section{Share of smokers that can be subsidized}

Revenue-neutral policy comparison implies that $12.20 \%$ of smokers can be subsidized under policy $\boldsymbol{P}$. This means policy $\boldsymbol{P}$ may cover 22 percent more smokers for treatment than $\boldsymbol{S}$ or $\boldsymbol{S}^{\prime}$ (Table 6).

Table 6. Share of smokers that can be subsidized under three policies

\begin{tabular}{|l|l|l|l|}
\hline & $\boldsymbol{S}^{\prime}$ & $\boldsymbol{S}^{\prime}$ & $\boldsymbol{P}$ \\
\hline \% smokers covered & 10 & 10 & 12.20 \\
\hline
\end{tabular}

Due to personalized medications, we identify a large extensive margin effect to cover more addicts with differential treatments based on genotypes.

\section{Quit rates}

Table 7 reports the quit rates of subsidized smokers under the three policies. 
Table 7. Quit rates under three policies (\%)

\begin{tabular}{|l|l|l|l|}
\hline & $\boldsymbol{S}$ & $\boldsymbol{S}^{\prime}$ & $\boldsymbol{P}$ \\
\hline mean & 45.17 & 38.48 & 45.17 \\
\hline H1 & 44.50 & 44.50 & 44.50 \\
\hline H2 & 45.39 & 38.66 & 45.39 \\
\hline H3 & 45.40 & 33.42 & 45.40 \\
\hline
\end{tabular}

Thus, quit rates under $\boldsymbol{S}$ and $\boldsymbol{P}$ are very close since everyone of the H2 or H3 type is treated with both counseling and medication. Quit rates under $\boldsymbol{S}^{\prime}$ is lower, as some of the H2 or H3 types only receive counseling which is less effective than a combination with medication. Moreover, H1 smokers must have the same quit rates under all policies, because medication does not play any additional role on their cessation outcome. By contrast, H2 and H3 benefit less from policy $\boldsymbol{S}^{\prime}$.

\section{Consumption Equivalent (CE) and Income Equivalent (IE)}

Table 8 reports Consumption Equivalent $(C E)$ and Income Equivalent $(I E)$ for subsidized smokers. In the table, $N$ means results under no policy intervention (hence no treatment) but with smokers' own attempt of cessation. ${ }^{14}$

Table 8. $C E$ and $I E$ of subsidized smokers (\%)

\begin{tabular}{|c|c|c|c|c|c|c|c|c|c|}
\hline$C E$ & $N$ & $S$ & $S^{\prime}$ & $P$ & $I E$ & $N$ & $S$ & $S^{\prime}$ & $P$ \\
\hline mean & 1.40 & 13.95 & 11.70 & 13.94 & mean & 1.08 & 10.74 & 9.03 & 10.74 \\
\hline H1 & 1.32 & 12.90 & 12.96 & 12.94 & $\mathrm{H} 1$ & 1.02 & 10.02 & 10.06 & 10.05 \\
\hline $\mathrm{H} 2$ & 1.36 & 13.61 & 11.49 & 13.59 & $\mathrm{H} 2$ & 1.0 & 10.55 & م 0 & 10.53 \\
\hline H3 & 1.53 & 15.25 & 11.01 & 15.23 & H3 & 1.16 & 11.60 & 8.37 & 11.58 \\
\hline
\end{tabular}

On average, $C E(I E)$ is about $14 \%(11 \%)$ under policy $\boldsymbol{S}$ or $\boldsymbol{P}$, but about 2 percentage points less under $\boldsymbol{S}^{\prime}$. The results suggest that the effectiveness of the former two policies is equivalent to increasing consumption by about $14 \%$, or income by bout $11 \%$, per year, to a subsidized smoker. Yet, policy $\mathbf{S}^{\prime}$ is not as effective, which is again mainly due to the worse-off of H2 and H3 types under $\boldsymbol{S}^{\prime}$ as some of them do not receive medication.

\footnotetext{
${ }^{14}$ Data shows success rate without treatment is about $5 \%$ for smokers who attempt to quit.
} 
Table 9 shows results for each demographic group by gender, race, and education, where the last six columns reports $C E$ 's and $I E$ 's under the three policies proposed. ${ }^{15}$

Table 9. Policy comparison by gender, race, and education (\%)

\begin{tabular}{|l|l|l|l|r|r|r|r|r|r|}
\hline $\mathrm{M}$ & $\mathrm{W}$ & $\mathrm{C}$ & $\%$ & $\boldsymbol{S}(C E)$ & $\boldsymbol{S}^{\prime}(C E)$ & $\boldsymbol{P}(C E)$ & $\boldsymbol{S}(I E)$ & $\boldsymbol{S}^{\prime}(I E)$ & $\boldsymbol{P}(I E)$ \\
\hline 0 & 0 & 0 & 5 & 6.36 & 5.94 & 6.37 & 4.97 & 4.64 & 4.97 \\
\hline 0 & 1 & 0 & 45 & 8.52 & 7.11 & 8.51 & 6.58 & 5.49 & 6.57 \\
\hline 0 & 0 & 1 & 0 & 27.43 & 25.00 & 27.44 & 21.18 & 19.31 & 21.19 \\
\hline 0 & 1 & 1 & 5 & 24.23 & 19.99 & 24.22 & 18.63 & 15.39 & 18.63 \\
\hline 1 & 0 & 0 & 7 & 6.82 & 6.33 & 6.84 & 5.32 & 4.94 & 5.33 \\
\hline 1 & 1 & 0 & 34 & 17.95 & 14.97 & 17.94 & 13.81 & 11.53 & 13.80 \\
\hline 1 & 0 & 1 & 1 & 32.61 & 29.78 & 32.61 & 25.18 & 23.01 & 25.19 \\
\hline 1 & 1 & 1 & 3 & 42.03 & 34.47 & 42.03 & 32.24 & 26.46 & 32.23 \\
\hline
\end{tabular}

Notice that the benefit of a policy (or cessation) increases with $\theta$, the work efficiency. As a consequence, $C E$ under $\boldsymbol{P}$, for example, varies from $6.36 \%$ for black, non-college, female smokers, to $42.03 \%$ for white, college, male smokers. The main reason is that a larger $\theta$ raises the opportunity cost of smoking, as better health makes people with higher work efficiency earn more, then consume more, invest more on health, and live longer (see Table 8). Moreover, demographic groups with a relatively larger share of $\mathrm{H} 2$ and $\mathrm{H} 3$ genotypes (e.g., the white groups) benefit relatively more from $\boldsymbol{P}$ than from $\boldsymbol{S}^{\prime}$.

\subsubsection{Summary}

To summarize the results of policy comparison, policy $\boldsymbol{S}$ and $\boldsymbol{P}$ have similar effects in terms of the quit rate and $C E$ or $I E$ for subsidized smokers, but $\boldsymbol{P}$ is able to cover $22 \%$ more smokers than $\boldsymbol{S}$, since it saves budget by not subsidizing H1-type smokers for medication while not reducing the effectiveness of treatment. Policy $\boldsymbol{S}^{\prime}$ is the least effective among the three, as it not only covers fewer smokers, but also results in a lower quit rate, and lower $C E$ or $I E$ (see rows 2-5 of Table 10).

We are now prepared to provide a unified measure of effectiveness. View the $10 \%$ or $12.20 \%$ subsidy rate as a lottery draw for subsidized treatment with probability $\pi=0.1$ or 0.122 . Then,

\footnotetext{
${ }^{15}$ Again, the proportions of three genotypes within each demographic group have been considered when computing the results.
} 
with probability $1-\pi$, a smoker would not be subsidized, whose decision remains unchanged and by construction their Consumption or Income Equivalent must be zero. One can therefore compute the expected $\mathrm{CE}$ of a smoker as: $\pi \cdot C E+(1-\pi) \cdot 0=\pi \cdot C E$. Similarly, the expected $I E$ of a smoker 1s: $\pi \cdot I E$. We further construct a dollar measure of effectiveness, multiplying $I E$ by average income of smokers, which is US $\$ 40,969$ at 2009 constant dollars (or, under $\theta=1,264$ efficiency wage units). Since average subsidy per smoker is $\$ 600 \cdot 0.1=\$ 60$, the cost/effective $(\mathrm{C} / \mathrm{E})$ ratio is simply $60 /(\pi \cdot I E)$. We report these three unified measures in the last three rows of Table 10.

Table 10. Summary of policy comparison (\% except the C/E ratio)

\begin{tabular}{|l|r|r|r|}
\hline & \multicolumn{1}{l|}{$\boldsymbol{S}$} & \multicolumn{1}{l|}{$\boldsymbol{S}^{\prime}$} & \multicolumn{1}{l|}{$\boldsymbol{P}$} \\
\hline \% subsidized & \multicolumn{1}{l|}{10} & 10 & 12.20 \\
\hline quit rate & 45.17 & 38.48 & 45.17 \\
\hline$C E$ of a subsidized smoker & 13.95 & 11.70 & 13.94 \\
\hline$I E$ of a subsidized smoker & 10.74 & 9.03 & 10.74 \\
\hline expected $C E$ of a smoker & 1.395 & 1.170 & 1.700 \\
\hline expected $I E$ of a smoker & 1.074 & 0.903 & 1.310 \\
\hline cost/effectiveness ratio $(\mathrm{C} / \mathrm{E})$ & $1 / 7.34$ & $1 / 6.16$ & $1 / 8.94$ \\
\hline
\end{tabular}

The results suggest that the expected gains from personalized treatment under $\boldsymbol{P}$ are $22-$ $45 \%$ higher than standard treatments under $\boldsymbol{S}$ and $\boldsymbol{S}^{\prime}$. Therefore, under the same program costs (subsidy), personalized treatment provides coverages for more, and maintain high effectiveness. For each dollar of subsidy, it generates 7.34 and 6.16 dollars Income Equivalent in effectiveness under standard treatments $\boldsymbol{S}$ and $\boldsymbol{S}^{\prime}$, but 8.94 dollars under personalized treatment $\boldsymbol{P}, 22 \%$ and $45 \%$ higher than under the two standard treatments. Hence, we conclude that personalized medication treatment is the most cost-effective.

\section{Conclusions}

To address the knowledge gap concerning cost-effectiveness of personalized medicine treatment in smoking cessation, we have developed a lifecycle model with smoking, health investment, savings and life expectancy all being determined endogenously. We have calibrated the model to fit key economics and medical observations and explored how cost-effective personalized treatment is 
compared to non-personalized treatments. We have shown that, under the same program costs, personalized treatment provides coverages for more and maintain high effectiveness. For each dollar of treatment subsidy, personalized treatment generates 8.94 Income Equivalent in effectiveness, $22-45 \%$ higher than those under standard treatments. We have therefore concluded that personalized treatment is the most cost-effective in smoking cessation.

To this end, we would like to acknowledge the limitation of our study. While we value health and quality of life, it is modeled as a gradual process. Should smoking result in lung cancer, the quality of life may be lowered sharply and medical cost raised suddenly. Thus, the actual private cost of smoking should be higher than that computed from the model. Moreover, we do not model social cost of smoking by modeling the negative externality such as second-hand smoking. We may thus underestimate the social benefit of cessation. Furthermore, smoking cessation is modeled as an instantaneous stop. Although by allowing for high dimensions of heterogeneity of demographic and genotype groups we well captured the heterogeneous process of smoking cessation, the resulting pain from quitting to an addict may lower her utility gain when quitting takes time. This may lead to underestimation of the private cost of cessation. On balance, based on both the economics and the medicine and health literature, it is expected that the first two effects outweigh the last. Thus, one may view our effectiveness figure as a conservative measure. 


\section{References}

[1] Adda, J. and F. Cornaglia, 2006. Taxes, cigarette consumption and smoking intensity. American Economic Review, 96(4), 1013-1028.

[2] Amos, C.I., Wu, X., Broderick, P., Gorlov, I.P., Gu, J., Eisen, T., Dong, Q., Zhang, Q., Gu, X., Vijayakrishnan, J. and Sullivan, K., 2008. Genome-wide association scan of tag SNPs identifies a susceptibility locus for lung cancer at 15q25. 1. Nature Genetics, 40(5), pp.616-622.

[3] Ashenfelter, O., M. Greenstone, 2004. Using mandated speed limits to measure the value of a statistical life. Journal of Political Economy, 112(S1), pp.S226-S267.

[4] Barendregt, J.J., Bonneux, L. and van der Maas, P.J., 1997. The health care costs of smoking. New England Journal of Medicine, 337(15), pp.1052-1057.

[5] Becker, G.S. and Murphy, K.M., 1988. A theory of rational addiction. Journal of Political Economy, 96(4), pp.675-700.

[6] Bergen, A.W., Javitz, H.S., Krasnow, R., Nishita, D., Michel, M., Conti, D.V., Liu, J., Lee, W., Edlund, C.K., Hall, S. and Kwok, P.Y., 2013. Nicotinic acetylcholine receptor variation and response to smoking cessation therapies. Pharmacogenetics and Genomics, 23(2), pp.94.

[7] Bloom, D.E., Canning, D. and Graham, B., 2003. Longevity and life-cycle savings. Scandinavian Journal of Economics 105(3), pp.319-338.

[8] Bough, K.J., Amur, S., Lao, G., Hemby, S.E., Tannu, N.S., Kampman, K.M., Schmitz, J.M., Martinez, D., Merchant, K.M., Green, C. and Sharma, J., 2014. Biomarkers for the development of new medications for cocaine dependence. Neuropsychopharmacology, 39(1), pp.202219 .

[9] Chakraborty, S., 2004. Endogenous lifetime and economic growth. Journal of Economic Theory, $116,119-137$.

[10] Chaloupka, F.J., 1990. Men, women, and addiction: the case of cigarette smoking (No. w3267). National Bureau of Economic Research.

[11] Chaloupka, F.J., 1991. Rational addictive behavior and cigarette smoking. Journal of Political Economy, 99(4), pp.722-742.

[12] Chaloupka, F.J. and Grossman, M., 1996. Price, tobacco control policies and youth smoking (No. w5740). National Bureau of Economic Research.

[13] Chaloupka, F.J. and Warner, K.E., 2000. The economics of smoking. Handbook of Health Economics, 1, pp.1539-1627.

[14] Chen, H.J., 2010. Life Expectancy, Fertility, and Educational Investment. Journal of Population Economics 23(1), pp. 37-56.

[15] Chen, L.S., Baker, T.B., Piper, M.E., Breslau, N., Cannon, D.S., Doheny, K.F., Gogarten, S.M., Johnson, E.O., Saccone, N.L., Wang, J.C. and Weiss, R.B., 2012. Interplay of genetic risk factors (CHRNA5-CHRNA3-CHRNB4) and cessation treatments in smoking cessation success. American Journal of Psychiatry, 169(7), pp.735-742. 
[16] Chen LS, Bierut LJ., 2013. Genomics and personalized medicine: and smoking cessation treatment. Journal of Food Drug Analysis, 21(4), pp.S87-S90.

[17] Chen, L.S., Hung, R.J., Baker, T., Horton, A., Culverhouse, R., Saccone, N., Cheng, I., Deng, B., Han, Y., Hansen, H.M. and Horsman, J., Kim, C., Lutz, S., Rosenberger, A., Aben, K.K., Andrew, A.S., Breslau, N., Chang, S.C., Dieffenbach, A.K., Dienemann, H., Frederiksen, B., Han, J., Hatsukami, D.K., Johnson, E.O., Pande, M., Wrensch, M.R., McLaughlin, J., Skaug, V., van der Heijden, H.F., Wampfler, J., Wenzlaff, A., Woll, P., Zienolddiny, S., Bickeb A., Heinrich, J., Hokanson, J.E., Hunter, D.J., Kiemeney, L.A., Lazarus, P., Le Marchand, L., Liu, G., Mayordomo, J., Risch, A., Schwartz, A.G., Teare, D., Wu, X., Wiencke, J.K., Yang, P., Zhang, Z.F., Spitz, M.R., Kraft, P., Amos, C.I., Bierut, L.J., 2015a. CHRNA5 risk variant predicts delayed smoking cessation and earlier lung cancer diagnosis - a meta-analysis. Journal of the National Cancer Institute, 107(5), p.djv100.

[18] Chen, L.S., Baker, T.B., Jorenby, D., Piper, M., Saccone, N., Johnson, E., Breslau, N., Hatsukami, D., Carney, R.M. and Bierut, L.J., 2015b. Genetic variation (CHRNA5), medication (combination nicotine replacement therapy vs. varenicline), and smoking cessation. Drug and Alcohol Dependence, 154, pp.278-282.

[19] Chen, L.S., Horton, A. and Bierut, L., 2016. Pathways to precision medicine in smoking cessation treatments. Neuroscience Letters.

[20] Costa, D.L. and Kahn, M.E., 2004. Changes in the value of life, 1940-1980. J. Risk and Uncertainty 29(2), pp.159-180.

[21] Ehrlich, I., 2000. Uncertain lifetime, life protection, and the value of life saving. Journal of Health Economics, 20(3), pp.341-367.

[22] Ehrlich, I. and Chuma, H., 1990. A Model of the Demand for Longevity and the Value of Life Extension. Journal of Political Economy, 98(4), pp.761-782.

[23] Ehrlich, I., Yin, Y., 2005. Explaining diversities in age-specific life expectancies and values of life saving: a numerical analysis. Journal of Risk and Uncertainty, 31(2), pp.129-162.

[24] Epstein, R.S., 2008. What's needed for personalized therapy in smoking cessation. Clinical Pharmacology \& Therapeutics, 84(3), pp.309-310.

[25] Furberg, H., Ostroff, J., Lerman, C. and Sullivan, P.F., 2010. The public health utility of genome-wide association study results for smoking behavior. Genome Medicine, 2(4), p.26.

[26] Giovino, G.A., Schooley, M.W., Zhu, B.P., Chrismon, J.H., Tomar, S., Peddicord, J.P., Merritt, R.K., Husten, C.G. and Eriksen, M., 1994. Surveillance for selected tobacco-use behaviorsUnited States, 1900-1994. Morbidity and Mortality Weekly Report 43, pp.1-43.

[27] Gold, A.B. and Lerman, C., 2012. Pharmacogenetics of smoking cessation: role of nicotine target and metabolism genes. Human Genetics, 131(6), pp.857-876.

[28] Gold, M. R., J. E. Siegel, L. B. Russell, M. C. Weinstein, eds., 1996. Cost-effectiveness in health and medicine. Report of the Panel on Cost-Effectiveness in Health and Medicine. New York: Oxford University Press.

[29] Green, E.D., Guyer, M.S. and Institute, N.H.G.R., 2011. Charting a course for genomic medicine from base pairs to bedside. Nature, 470(7333), pp.204-213. 
[30] Grossman, M., 1972a. The Demand for Health: A Theoretical and Empirical Investigation. Columbia University Press for the National Bureau of Economic Research, New York.

[31] Grossman, M., 1972b. On the concept of health capital and the demand for health. Journal of Political Economy, 80(2), pp.223-255.

[32] Grossman, M. and Kaestner, R., 1997. Effects of Education on Health. in J.R. Berhman and N. Stacey (eds.) The Social Benefits of Education, 12, pp.69. Ann Arbor: University of Michigan Press.

[33] Hall, R.E. and Jones, C.I., 2007. The value of life and the rise in health spending. Quarterly Journal of Economics, 122(1), pp.39-72.

[34] Halld B., Engstr Gene variance in the nicotinic receptor cluster (CHRNA5-CHRNA3CHRNB4) predicts death from cardiopulmonary disease and cancer in smokers. Journal of Internal Medicine.

[35] Jha, P., Ramasundarahettige, C., Landsman, V., Rostron, B., Thun, M., Anderson, R.N., McAfee, T. and Peto, R., 2013. 21st-century hazards of smoking and benefits of cessation in the United States. New England Journal of Medicine, 368(4), pp.341-350.

[36] Jones C., 2016. Life and Growth. Journal of Political Economy, 124(2), pp.539-578.

[37] Kenkel, D.S., 1991. Health behavior, health knowledge, and schooling. Journal of Political Economy, 99(2), pp.287-305.

[38] Knopik, V.S., Maccani, M.A., Francazio, S. and McGeary, J.E., 2012. The epigenetics of maternal cigarette smoking during pregnancy and effects on child development. Development and Psychopathology, 24(04), pp.1377-1390.

[39] Kortmann, G.L., Dobler, C.J., Bizarro, L. and Bau, C.H., 2010. Pharmacogenetics of smoking cessation therapy. American Journal of Medical Genetics Part B: Neuropsychiatric Genetics, 153(1), pp.17-28.

[40] Kupiainen, H., Kuokkanen, M., Kontto, J., Virtamo, J., Salomaa, V., Lindqvist, A., Kilpel 2016. CHRNA5/CHRNA3 locus associates with Increased mortality among smokers. COPD. Journal of Chronic Obstructive Pulmonary Disease, 13(4), pp.464-470.

[41] Liu, J.Z., Tozzi, F., Waterworth, D.M., Pillai, S.G., Muglia, P., Middleton, L., Berrettini, W., Knouff, C.W., Yuan, X., Waeber, G. and Vollenweider, P., 2010. Meta-analysis and imputation refines the association of $15 q 25$ with smoking quantity. Nature Genetics, 42(5), pp.436-440.

[42] Lleras-Muney, A., 2005. The relationship between education and adult mortality in the United States. Review of Economic Studies, 72(1), pp.189-221.

[43] Max, W., Rice, D.P., Sung, H.Y., Zhang, X. and Miller, L., 2004. The economic burden of smoking in California. Tobacco Control, 13(3), pp.264-267.

[44] McClure, J.B., Swan, G.E., John, J.S., Fauver, R., Javitz, H.S., Bergen, A.W., Nishita, D., Niaura, R., Munaf and David, S.P., 2013. Pharmacogenetic smoking cessation intervention in a health care setting: a pilot feasibility study. Nicotine \& Tobacco Research, 15(2), pp.518-526.

[45] Miller, V.P., Ernst, C. and Collin, F., 1999. Smoking-attributable medical care costs in the USA. Social Science \& Medicine, 48(3), pp.375-391 
[46] Murphy, K.M. and Topel, R.H., 2006. The value of health and longevity. Journal of Political Economy, 114(5), pp.871-904.

[47] Pickett, M.S., Schober, S.E., Brody, D.J., Curtin, L.R., Giovino, G.A., 2006. Smoke-free laws and secondhand smoke exposure in US non-smoking adults, 1999-2002. Tobacco Control, 15(4), pp. 302-307.

[48] Pillai, S.G., Ge, D., Zhu, G., Kong, X., Shianna, K.V., Need, A.C., Feng, S., Hersh, C.P., Bakke, P., Gulsvik, A. and Ruppert, A., 2009. A genome-wide association study in chronic obstructive pulmonary disease (COPD): identification of two major susceptibility loci. PLoS Genet, 5(3), p.e1000421.

[49] Rosen, S., 1988. The value of changes in life expectancy. Journal of Risk and Uncertainty, 1(3), pp.285-304.

[50] Saccone, N.L., Culverhouse, R.C., Schwantes-An, T.H., Cannon, D.S., Chen, X., Cichon, S., Giegling, I., Han, S., Han, Y., Keskitalo-Vuokko, K. and Kong, X., 2010. Multiple independent loci at chromosome 15q25. 1 affect smoking quantity: a meta-analysis and comparison with lung cancer and COPD. PLoS Genet, 6(8), p.e1001053.

[51] Sturgess, J.E., George, T.P., Kennedy, J.L., Heinz, A. and M and drug addiction treatments. Addiction Biology, 16(3), pp.357-376.

[52] Tanner, J.A., Chenoweth, M.J. and Tyndale, R.F., 2015. Pharmacogenetics of nicotine and associated smoking behaviors. In The Neurobiology and Genetics of Nicotine and Tobacco (pp. 37-86). Springer International Publishing.

[53] Thorgeirsson, T.E., Gudbjartsson, D.F., Surakka, I., Vink, J.M., Amin, N., Geller, F., Sulem, P., Rafnar, T., Esko, T., Walter, S. and Gieger, C., 2010. Sequence variants at CHRNB3CHRNA6 and CYP2A6 affect smoking behavior. Nature Genetics, 42(5), pp.448-453.

[54] Thorgeirsson, T.E., Geller, F., Sulem, P., Rafnar, T., Wiste, A., Magnusson, K.P., Manolescu, A., Thorleifsson, G., Stefansson, H., Ingason, A. and Stacey, S.N., 2008. A variant associated with nicotine dependence, lung cancer and peripheral arterial disease. Nature, 452(7187), pp.638-642.

[55] Tobacco and Genetics Consortium, 2010. Genome-wide meta-analyses identify multiple loci associated with smoking behavior. Nature Genetics, 42(5), pp.441-447.

[56] van Ours, J.C., 2004. A pint a day raises a man's pay; but smoking blows that gain away. Journal of Health Economics, 23(5), pp.863-886

[57] Volpp, K.G., Troxel, A.B., Pauly, M.V., Glick, H.A., Puig, A., Asch, D.A., Galvin, R., Zhu, J., Wan, F., DeGuzman, J. and Corbett, E., 2009. A randomized, controlled trial of financial incentives for smoking cessation. New England Journal of Medicine, 360(7), pp.699-709.

[58] Whiteford, H.A. and Baxter, A.J., 2013. The Global Burden of Disease 2010 Study: what does it tell us about mental disorders in Latin America?. Revista Brasileira de Psiquiatria, 35(2), pp.111-112.

[59] World Health Organization, 2011. Economics of Tobacco Toolkit: Assessment of the economic costs of smoking. 

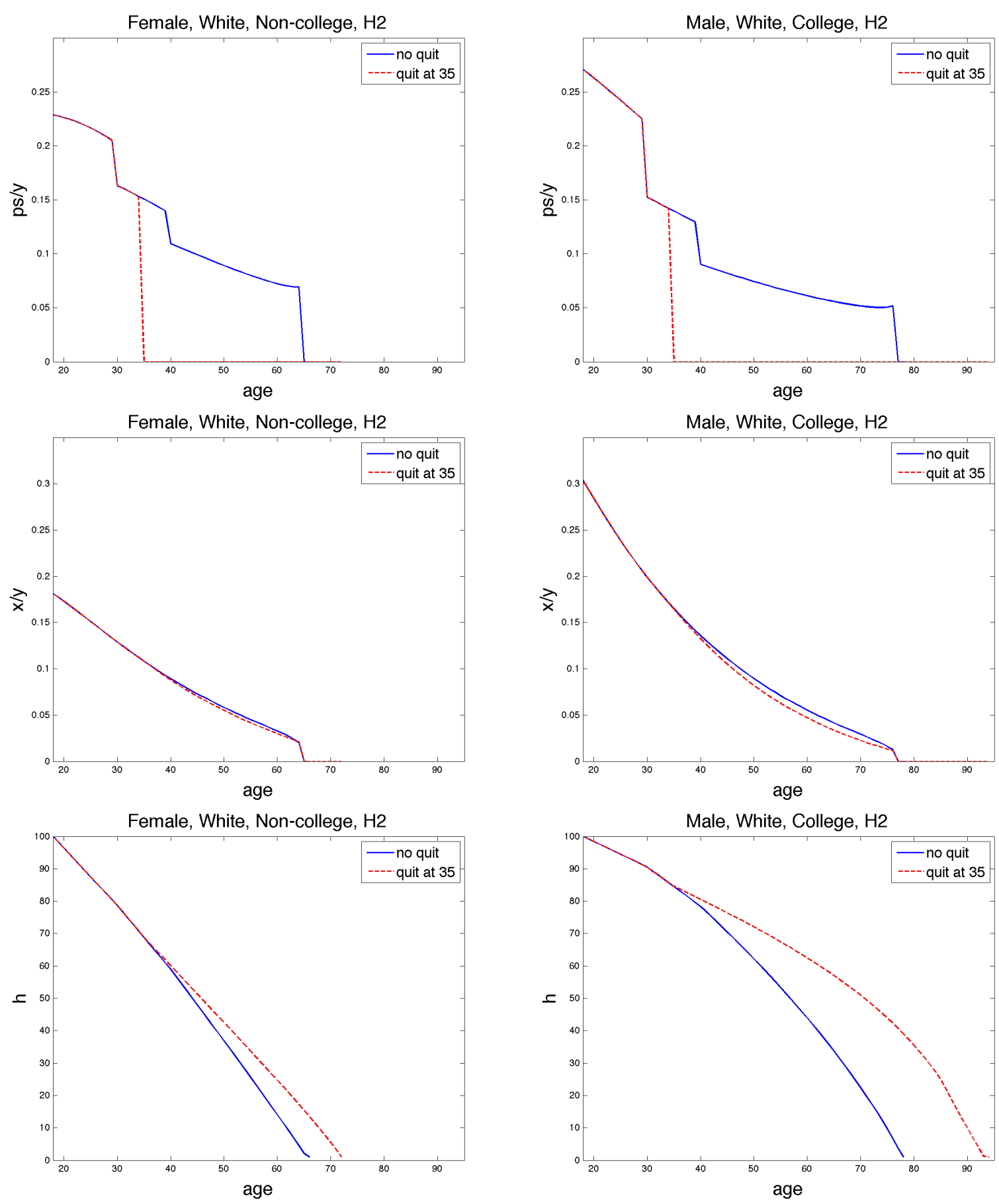

Figure 1. Lifecycle profile of smoking, health investment, and health capital 